\title{
Editor biographies
}

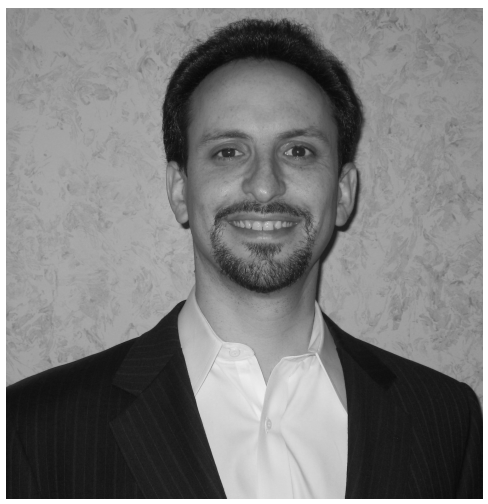

tion for this book. He has served on several editorial boards and as the guest editor for a number of professional journals, as well as on review panels with the US National Security Education Program. Dr Kessler has published or presented over 100 scholarly papers in top academic outlets and conferences, won numerous research and teaching awards, and is the author or editor of several additional books including Handbook of Organizational and Managerial Wisdom (2007, Sage Publications) and Management Theory in Action (forthcoming, Palgrave Macmillan). He is a member of Phi Beta Kappa and has been inducted into national and international honour societies in Business, Economics, Forensics, and Psychology. Professor Kessler instructs courses on the doctoral, masters, and bachelors levels, has led several international field studies, and has worked as an executive educator, policy analyst, and business consultant for public and private organizations. His professional travels have taken him across the six continents represented in this volume. Eric is an avid reader of history and philosophy, a sports and puzzle junkie, as well as the spinner of many a bad pun. He lives with his best friend/wife, two terrific sons, and faithful Black Labrador. 


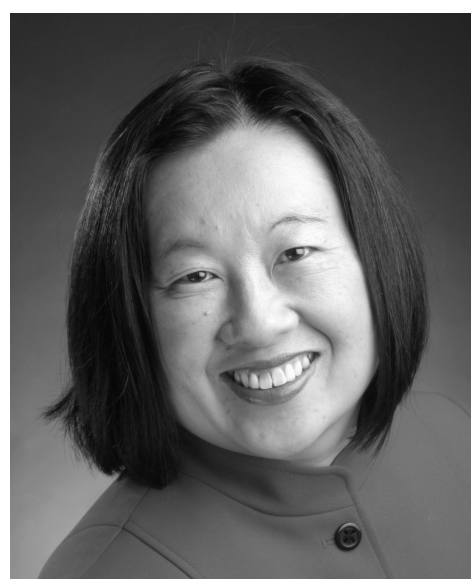

Diana J. Wong-MingJi, Ph.D., is an Associate Professor of Strategy and Entrepreneurship at Eastern Michigan University. She also teaches international management, leadership, and organization development and change. Her research examines how strategic alliances evolve through different competitive conditions and the related development of leadership competencies to manage change. In particular, Diana is interested in organizational change processes related to globalization. Her international experiences include studying indigenous communities while attending the University of Oslo in Norway, working with negotiating teams on subsidies for the US-Canada Free Trade Agreement and later NAFTA; teaching in Papua New Guinea and China; and launching an international education agreement between Eastern Michigan University and Osmania University in India. Her professional activities include contributing to the internationalization of organizations, serving as President of the American Society of Training and Development's Ann Arbor chapter, and consulting through her practice, Sensei Change Associates. Currently, Diana resides in Ann Arbor, MI with her family and spends most summers in Vancouver, Canada. 